\title{
A responsabilidade civil e as lições aprendidas no desastre do rompimento da barragem de Miraí-MG.
}

\author{
Civil liability and the lessons learned in the \\ disaster of the rupture of the barrier of Miraí-MG.
}

Marcos Vinicius Rodrigues Escola Superior Dom Helder Câmara - ESDHC

Resumo Este estudo analisa aspectos da responsabilidade civil no caso do dano ambiental com o rompimento da barragem de uma empresa de mineração em Miraí-MG, no ano de 2007. Far-se-á uma análise do desastre ambiental e as implicações sobre o prisma da responsabilidade civil e, em que medida tal aprendizado pode ser estendido ao desastre recentemente ocorrido em Mariana-MG. Utilizando-se do método dedutivo, foi feito um estudo, consultando a análise doutrinária, artigos e sítios eletrônicos. Por fim, conclui-se que com base no princípio da responsabilidade, a efetivação das decisões judiciais prolatadas pelo Poder Judiciário, relativas à apuração da responsabilidade civil da empresa envolvida no acidente em Miraí foi um importante instrumento, contudo, passou desapercebida como aprendizado na orientação de novos empreendimentos, e os devidos cuidados e responsabilidade com a construção e manutenção de barragens.

Palavras-chave: Responsabilidade Civil. Rompimento de BarRagens. Acidente de Miraí-MG.

Abstract This study examines aspects of civil liability in the case of environmental damage with the rupture of the barrier of a mining company in Miraí-MG, in the year 2007. There will be a review of the en- 
vironmental disaster and the implications on the prism of civil liability and the extent to which such learning can be extended to the disaster recently took place in Mariana, MG. Using the deductive method, a study has been conducted, with doctrinal analysis, articles and electronic sites. Finally, it is concluded that based on the principle of responsibility, the realization of judicial decisions prolatadas by the Judiciary, relating to the determination of the civil liability of the company involved in the accident in Miraí was an important instrument, however, passed unnoticed as learning in the orientation of new enterprises, and the proper care and responsibility for the construction and maintenance of dams.

Keywords: Civil liability. DisRuption of Dams. An accident of Miraí-MG.

\section{INTRODUÇÃO}

Uma grande barragem de dejetos de mineração rompeu-se e um mar de lama se formou e devastou tudo em seu caminho, afetando inúmeras áreas rurais e urbanas. Muitos afetados sequer tiveram tempo de salvar os seus pertences.

A sucinta descrição acima de uma tragédia remete também ao caso ocorrido em Miraí-MG, no ano de 2007, consequência do rompimento da barragem de mineração, e também com profunda repercussão nas vidas dos afetados na região de Miraí em Minas Gerais.

Resultou do desastre da barragem da empresa Mineração Rio Pomba Cataguases, o derramamento aproximadamente dois bilhões de resíduos de lama tóxica, contendo bauxita, caracterizando à época, como o maior acidente ambiental da região.

Neste diapasão, a pergunta de partida que a pesquisa intenta responder é a seguinte: em que medida as lições aprendidas com o desastre, especificamente as sanções civis, e em função da responsabilidade civil, aplicadas em desfavor da empresa responsável pelo dano ambiental em Miraí servirão de modelo nas ações para ressarcir o desastre aos recursos naturais e à população no desastre ocorrido em Mariana - MG.

Dentre as várias ações, o Supremo Tribunal de Justiça, em sede de recurso repetitivo, julgou o REsp 1374284 / MG, o qual se pode inferir 
a linha a ser adotada nos casos envolvendo responsabilidade civil por dano ambiental para o mesmo incidente. Conjectura-se que o comportamento das ações relativas ao acidente parecido ocorrido em Mariana, em 2015, resulte em um tratamento análogo ao que aconteceu em Miraí. O que, dado a dimensão do número de afetados em Miraí, e frente a justificativa de que a empresa causadora do dano não teria condições de arcar com todos os processos, resultou em um valor de responsabilização muito abaixo do esperado pelos afetados.

É de se refletir, contudo, se na fixação do valor da indenização, mesmo no aspecto da responsabilidade individual, não se deveria considerar algum grau punitivo para o causador do dano, como medida para evitar a reiteração da conduta, e como historicamente vem sendo verificado, tem se repetido ao longo dos anos em Minas Gerais. O dilema está na fixação do valor da indenização em detrimento da necessidade de preservar a continuidade da empresa.

Este trabalho propõe-se, assim, a investigar a questão da responsabilidade civil por dano ambiental no caso do rompimento da barragem de Miraí e, ainda, a possibilidade de que as indenizações para o caso da tragédia de Mariana, tenham um tratamento análogo. Utilizando-se do método dedutivo, foi feito um estudo, consultando a análise doutrinária, artigos e sítios eletrônicos. Buscar-se-á, valendo-se de método dedutivo, por meio da análise doutrinária, artigos e sítios eletrônicos, analisar, para o caso em tela, a aspectos da teoria da responsabilidade civil por dano ambiental.

Para tanto, o artigo foi dividido em quatro partes, além da introdução e da conclusão. Inicialmente, será feita uma análise do princípio da responsabilidade, sobre o fulcro do dever objetivo de que aquele que polui deve responder pelas consequências e custos sociais da degradação causada por sua atividade impactante. Nos dois tópicos seguidos, serão examinadas as particularidades do dano ambiental ocorrido com o rompimento de barragem em Miraí e a responsabilização civil da empresa responsável, tomando-se por base o REsp 1374284/MG, e em outro tópico, a questão da responsabilidade civil e o recente acidente de Mariana-MG, ao final, serão apresentadas, na seara da responsabilidade civil, as lições 
aprendidas com o caso de Miraí e a refletir sobre as perspectivas da responsabilidade que serão aplicadas no caso de Mariana-MG.

\section{As EMPRESAS E O PRINCíPIO da RESPONSABILIDADE No DIREITO AMBIENTAL}

Antes de abordarmos propriamente a Responsabilidade Civil no desastre de Miraí, é pertinente destacar um dos princípios do Direito Ambiental relevantes à discussão do tema, que consiste no Princípio da Responsabilidade, que também é utilizado por muitos autores como sinônimo do Princípio do Poluidor-pagador, o qual, em síntese, trata-se do ditame que prevê que todos aqueles que causam degradação ambiental, devem arcar com os custos sociais da degradação causada.

O princípio possui duas vertentes doutrinárias, a saber, a preventiva, que objetiva evitar a ocorrência de danos ambientais, de outro lado, há o entendimento da natureza sancionadora, que é mais evidente em sua definição, e busca a reparação do dano já ocorrido (SOUSA, 2016, p.1). Em alusão aos casos de rompimento de barragens, vamos nos ater à segunda tese.

O princípio da responsabilidade faz com que os responsáveis pela degradação ao meio ambiente sejam obrigados a arcar com a responsabilidade e com os custos da reparação ou da compensação pelo dano causado. Esse preceito pode ser verificado no $\S 3^{\circ}$ do art. 225 da Constituição Federal.

A propósito do princípio da responsabilidade, Benjamin (1993, p. 7) ensina que:

Ao contrário do que se imagina, o princípio poluidor-pagador não se resume na fórmula "poluiu, pagou". "O princípio poluidor-pagador não é um princípio de compensação dos danos causados pela poluição".

Seu alcance é mais amplo, incluídos todos os custos da proteção ambiental, "quaisquer que eles sejam", abarcando, a nosso ver, os custos de prevenção, de reparação e de repressão do dano ambiental, assim como 
aqueles outros relacionados com a própria utilização dos recursos ambientais, particularmente os naturais, que "têm sido historicamente encarados como dádivas da natureza, de uso gratuito ou custo marginal zero"

Extrai-se do princípio em voga, que as condutas que causem determinado dano ambiental, submetem às sanções penais e administrativas, da mesma forma, os sujeitos ativos ou omissos na causa do dano, ou mesmo na possibilidade de evitar o dano. Assim, no direito ambiental, as penalidades são aplicadas sem o prejuízo do dever de indenização civil diante dos danos causados. Dessarte, independentemente da indenização de natureza civil, as ações contra o meio ambiente, ensejam também punições em outras searas como também a criminal e a administrativa. Logo, a responsabilidade por danos ambientais em regra é objetiva.

$\mathrm{Na}$ seara do direito ambiental, a responsabilidade em civil é dividida em administrativa e penal. Na responsabilidade civil, ressalta-se o entendimento de que esta será sempre objetiva, ou seja, independerá de dolo ou culpa comprovada do agente que a praticou. Esta responsabilidade tem pressupostos que a constituem e demonstrados através do evento danoso e do nexo de casualidade com a fonte poluidora (BOUTH, 2011, p.1).

Assevera-se que as penalidades criminais e administrativas que decorrem deste princípio não se limitam à esfera civil, no tocante a este item, a título de exemplo temos as penas aplicáveis às pessoas jurídicas como espécie de prestação de serviços à comunidade, ou mesmo a execução de obras na tentativa de recuperar de áreas afetadas, consoante ao artigo 23, II, da Lei 9.605/1998 (AMADO, 2014, p.262).

A partir deste princípio infere-se também que quem polui deve responder pelas consequências e custos sociais da degradação causada por sua atividade impactante. Deve-se frisar ainda que pode ser entendido como um instrumento econômico que exige do poluidor, uma vez identificado, suportar as despesas de prevenção, reparação e repressão pelas consequências ao meio ambiente. 
Neste diapasão, para a aplicação do princípio, os custos sociais externos, valor econômico, que acompanham o processo de produção devem ser internalizados, ou seja, o custo resultante da poluição deve ser contabilizado, ao custo da produção, pelos responsáveis de atividades potencialmente poluidoras. Desta forma, quem poluir tem a responsabilidade de suportar os custos necessários à diminuição, eliminação ou neutralização do dano ambiental (SILVA, 2015, p.73).

Ainda neste bojo, conexo à responsabilidade de uma empresa e a desconsideração da personalidade jurídica, cumpre observar o artigo $3^{\circ}$, parágrafo único e artigo $4^{\circ}$ da lei $9605 / 98$. Desta forma, nos crimes ambientais a personalidade jurídica não impedirá o ressarcimento de prejuízos causados ao meio ambiente.

Em síntese, sustenta-se a tese de que uma responsabilidade não exclui a outra, devendo ser aplicadas em conjunto, cada qual à sua maneira e como forma de coibir novos desastres. Nesta linha, podemos ilustrar a lição de Milaré (2007, p. 819) que esclarece "Como se vê, os atos atentatórios ao ambiente têm (ou podem ter) repercussão jurídica tripla, já que ofendem o ordenamento de três maneiras distintas".

Efetuado este importante registro sobre o princípio da responsabilidade no Direito Ambiental, por extensão, salienta-se o papel das empresas mineradoras e suas responsabilidades ambientais, em especial, no tratamento de rejeitos e manutenção de reservatórios. Afinal, não se espera limitar as atividades destas empresas bem como o desenvolvimento, sobremaneira, deve ser pensado de maneira sustentável a atividade e a conservação dos recursos ambientais como forma de evitar desastres ambientais com barragens como se tem registrado reiteradamente ao longo dos anos.

Da mesma forma, o Judiciário na defesa do princípio da responsabilidade, deve ser atuante ao lidar em questões análogas, e "intervir em decisões que colocassem o meio ambiente em risco, responsabilizando-se por um cuidado de longo prazo que políticos eleitos poderiam não ter, tendo em vista o pensamento de curto prazo das eleições seguintes" (MACHADO, 2016, p.264). 
Assim, cumpre salientar que o princípio da responsabilidade assenta no preceito de que o autor do prejuízo, seja ele pessoa física ou jurídica, deve responder por sua conduta, configurada a partir de ações ou omissões relacionadas à sua responsabilidade, o qual, decorra em dano ao meio ambiente, por sua vez, não podendo prescindir da devida repreensão, seja na esfera criminal, administrativa, bem como na obrigação responsabilização civil.

\section{A responsabilidade civil e o acidente de Miraí}

Remonta à madrugada do dia 10 de janeiro de 2007, o desastre que ficou conhecido como o Acidente de Miraí-MG, onde uma barragem de rejeitos do empreendimento minerário, Mineração Rio Pomba Cataguases Ltda., localizado na zona rural do Município de Miraí, rompeu-se, e cerca de 2 bilhões de litros de resíduos contaminados por bauxita vazaram da barragem da empresa após uma forte chuva, e por conseguinte, causaram sérios danos ambientais nos Municípios ao longo da bacia do rio Fubá, trazendo consequências além de Miraí, em várias cidades de Minas Gerais e do Rio de Janeiro (LARCHER, 2012, p.1).

Sobremodo, os maiores danos ambientais e materiais foram sentidos no Município de Miraí. No entanto, estima-se que cerca de 16.000 (dezesseis mil) pessoas tenham ficado desabrigadas em razão do rompimento da barragem de rejeitos de bauxita. Vale mencionar ainda a destruição da ictiofauna do rio Fubá, o corte do abastecimento de água na região e a destruição de propriedades rurais e plantações, além do fechamento de estradas (LARCHER, 2012, p.1).

A ocorrer tal fato, as investigações concluíram que houve uma falha na estrutura da barragem o qual não corrigida pela empresa, sendo concluído que a mineradora foi responsável pelo acidente. Além de Termo de Ajustamento de Conduta firmado com os Ministério Público Federal e Estaduais de Minas Gerais e do Rio de Janeiro, com o dever de realizar um diagnóstico ambiental e a execução de Planos de Recuperação da área afetada, diante da situação, foram adotadas ações emergenciais para a contenção da barragem de rejeitos no local do 
rompimento e minimizar os danos e os riscos à população e ao meio ambiente, sendo estabelecido a obrigação da empresa encerrar a exploração de bauxita no local e um período de até 180 dias (FERREIRA; SANTO, 2017, p.5).

Outra medida, foi a exigência de um plano de recuperação das áreas degradadas, cabendo a monitoração diária da qualidade da água por 90 dias, e semanalmente monitorar elementos tóxicos liberados pelo vazamento. Ainda, para a o ressarcimento das vítimas por danos morais e materiais, a empresa ficou incumbida de instalar representações nos municípios atingidos. Como garantia das obrigações a serem cumpridas, a mineradora teve que depositar R $\$ 2$ milhões em conta judicial (FERREIRA; SANTO, 2017, p.5).

No plano judicial, após a interposição de vários processos: 3.938 ações envolvendo a mineradora no município de Muriaé e outras 500 em Miraí, em sede já da instância no Superior Tribunal de Justiça, STJ, foi decidido, de forma a orientar a solução de processos idênticos que tramitam nas instâncias inferiores (recurso repetitivo) que a Mineração Rio Pomba Cataguases deveria recompor os danos materiais e morais que aconteceram após o vazamento de lama tóxica (STJ, 2014, p.1).

Em sua defesa, e conforme o REsp 1374284/MG, a empresa Mineração Rio Pomba Cataguases sustentou o afastamento da responsabilidade com fulcro na não comprovação do nexo de causalidade entre o rompimento da barragem e os danos sofridos pela vítima. Alegando ainda a ocorrência de força maior, como as fortes enchentes na região, em períodos anteriores, que afastaria o nexo causal determinante, capaz de justificar a indenização.

Com efeito, a justificativa da empresa mineradora diante do Recurso em tela não prosperou, face as considerações aduzidas, o entendimento do eminente relator Ministro Luís Felipe Salomão respaldou que "o que determina o dano moral indenizável é a consequência, o resultado que do ato emana. Não é o ato em si que dirá se ele é ressacável, mas os efeitos que o dano provoca". Ampara também a refutação do pedido de recurso, a argumentação de que foram de fato comprovados os infor- 
túnios sofridos pelos moradores afetados oriundos do ato ilícito alçado pela mineradora (SUPREMO TRIBUNAL DE JUSTIÇA, 2014).

Por conseguinte, no âmbito do mesmo Recurso Especial, o entendimento do STJ, foi orientado nos termos da responsabilidade objetiva para o dano ambiental, e em concordância com a teoria do risco integral. Em síntese, os ministros, tomando por base os processos já julgados, entenderam descabida invocar, excludentes de responsabilidade civil para afastar a sua obrigação de indenizar, e que de fato, existe uma relação causal entre o rompimento da barragem, com vazamento de resíduos químicos, e os danos sofridos pelas vítimas. Por fim, a decisão, condenou a empresa a reparar os danos materiais e morais causados às famílias que ingressaram na Justiça (STJ, 2014, p.1).

Nessa linha, é salutar a consolidação do entendimento sobre o assunto, a partir do avanço introduzido pelo Código Civil, que, em matéria de responsabilidade civil, foi concebida como objetiva. Ademais, em matéria ambiental, coube à Lei $n^{\circ}$ 6.938/81, que instituiu a Política Nacional do Meio Ambiente, evidenciar o princípio da responsabilidade objetiva em detrimento do princípio da responsabilidade subjetiva, tendo como arcabouço, o elemento culpa, pelo da responsabilidade objetiva, que se baseia no risco da atividade (SILVA, 2007, p.1).

Ao estabelecer a responsabilidade civil ambiental, e consequentemente a obrigação de indenizar, urge identificar o sujeito, o ato ou fato (causa), bem como o vínculo entre o ato ou fato imputável ao sujeito e o dano causado. Assim, a tutela individual estará presente todas as vezes que o meio ambiente se encontra protegido pela tutela jurisdicional, como nos casos de obrigação de reparar, resultante de atos ilícitos. Ainda, a extensão dos prejuízos, no entanto, dependerá de ação própria para ser constatada, sendo cabível aos interessados provar concretamente que o rompimento da barragem de rejeitos foi responsável pelos prejuízos cuja indenização pleiteiam (SILVA, 2007, p.1).

Como se denota, a responsabilidade objetiva, tem base na teoria do risco da atividade, e para a responsabilização, basta demonstrar o evento danoso e o nexo de causalidade para a responsabilização daquele que causou ou de alguma forma contribuiu para o dano ambien- 
tal. Sendo o princípio da responsabilidade um importante instrumento para enunciar destacada regra do nosso ordenamento jurídico de modo a orientar as atividades dos empreendimentos, e no nosso caso peculiar em análise, os devidos cuidados e responsabilidade com a construção e manutenção de barragens.

\section{A responsabilidade Civil e o aCidente de Mariana}

O recente, e maior, desastre ambiental já ocorrido no Brasil, foi também motivado pelo rompimento de uma barragem de rejeitos, e ocorreu em Mariana-MG, no Complexo minerário da empresa Samarco, onde o efeito devastador da enxurrada de lama de rejeitos de mineração também atingiu diversas cidades e afetou a bacia do Rio Doce. Tal acontecimento, também inundou os tribunais com vários processos na busca pela sanção penal, administrativa e civil, e apuração da responsabilidade socioambiental das empresas envolvidas nesse evento (PISKE, 2016, p.1).

Diante da circunstância e das proporções do acidente, a responsabilidade por dano ambiental passou a ter uma dimensão de extrema relevância nos cenários social, econômico, político e jurídico por representar, mais um grave acidente envolvendo a exploração de uma tradicional e significativa atividade econômica para o país, a minerária.

Assim, a responsabilidade civil por dano ambiental perpassa as funções: punitiva, reparatória e preventiva, e também uma quarta (SANTIAGO; SANTOS; ADAME, 2016, p. 12):

A função social, vinculada aos princípios da responsabilidade social e da solidariedade social, surgidos com a superação do individualismo que caracterizava as relações econômicas. Haja vista a proporção do dano e a complexidade de envolvidos/afetados pelo desastre (STEIGLEDER, 2011, p. 156).

Resta claro, portanto, que com ênfase no princípio da responsabilidade mais uma vez temos a regra de que o responsável pelo dano é 
"obrigado, independentemente da existência de culpa, a indenizar ou reparar os danos causados ao meio ambiente e a terceiros, afetados por sua atividade". Restando claro e evidenciado o alcance da aplicação da responsabilidade civil objetiva a Samarco, Vale e BHP Biliton, vez que já foram levantadas várias provas na responsabilização pelo desastre e produção do dano conexa a atividade mineradora, especificamente, no devido cuidado com a contenção de rejeitos minerais pela barragem (SANTIAGO; SANTOS; ADAME, 2016, p. 12).

Ampliando o pensamento, no entendimento do STJ diante da análise do julgamento do REsp 1.373.788/SP, de Relatoria do Ministro Paulo de Tarso Sanseverino, observa-se entendimento na previsão de indenizar o dano, independentemente de culpa, restando comprovados os danos ambientais, com fulcro no artigo 927 do Código Civil Brasileiro e o artigo 14, parágrafo $1^{\circ}$ da Lei 6.938/1981, senão vejamos:

"DIREITO AMBIENTAL. RESPONSABILIDADE CIVIL OBJETIVA POR DANO AMBIENTAL PRIVADO.

A responsabilidade civil por danos ambientais, seja por lesão ao meio ambiente propriamente dito (dano ambiental público), seja por ofensa a direitos individuais (dano ambiental privado), é objetiva, fundada na teoria do risco integral, em face do disposto no art. $14, \S 1^{\mathrm{o}}$, da Lei 6.938/1981, que consagra o princípio do poluidor-pagador. A responsabilidade objetiva fundamenta-se na noção de risco social, que está implícito em determinadas atividades, como a indústria, os meios de transporte de massa, as fontes de energia. Assim, a responsabilidade objetiva, calcada na teoria do risco, é uma imputação atribuída por lei a determinadas pessoas para ressarcirem os danos provocados por atividades exercidas no seu interesse e sob seu controle, sem que se proceda a qualquer indagação sobre o elemento subjetivo da conduta do agente ou de seus prepostos, bastando a relação de causalidade entre o dano sofrido pela vítima e a situação de risco criada pelo agente..." (SUPREMO TRIBUNAL DE JUSTIÇA, 2014, p.1). 
No caso em voga, é cediço o reconhecimento da aplicação da responsabilidade civil objetiva, mas, o valor a ser pago pela mineradora é, por ora, incalculável. Tamanho o desastre que torna prejudicada a identificação hábil de toda a extensão do dano e muito menos os seus efeitos. Todavia, a Samarco já teve bloqueados R $\$ 300$ milhões de reais por ordem judicial da Comarca de Mariana e fez acordo preliminar com o MPF e o MPE no valor de R \$ 1 bilhão para o custeio de medidas preventivas de contenção de danos e também para o pagamento de indenizações em decorrência do rompimento da barragem (FREITAS, 2016, p.1).

Por ultimato, é cabível aclarar que nestes casos, temos o desafio do efetivo alcance da responsabilidade por todos os atos resultantes do desastre ambiental, afinal, houve enormes consequências sociais, já que "a lama de ferro destruiu também patrimônio histórico-cultural, a exemplo de casas construídas em séculos passados, praças, museus e escolas, exterminando um passado, sem deixar vestígios do que foi um dia" (BELCHIOR; BRAGA; THEMUDO, 2016, p. 115).

Apesar da inafastável responsabilização objetiva pelo dano, efetuando um paralelo com o desastre acontecido em Miraí-MG, e, apesar da maior proporção do desastre acontecido em Mariana-MG, estima-se que as sanções civis a serem aplicadas em desfavor da empresa Samarco pelos danos ambientais, serão norteadas pelas mesmas premissas e consequentemente resultarão em um resultado similar ao aplicado à Empresa de mineração Rio Pomba Cataguases. Quais sejam, limitados serão insuficientes para ressarcir o desastre aos recursos naturais e a história da população atingida.

Por oportuno, é salutar que o Estado através da aplicação da Justiça compreenda o significado dos direitos inserida na valoração dos direitos sócias e o reconhecimento aos novos sujeitos e suas novas identidades. Essa compreensão vincula-se à noção, cunhada por Arendt, de “... direitos a ter direitos” (DIAZ; SANTOS JÚNIOR, apud BODSTEIN, 2017, p. 3). Importa, o debate em razão da aplicação da responsabilidade civil também como forma de nortear a gestão das empresas na construção de um meio ambiente sustentável e maior compromisso 
social e respeito à dignidade humana no desempenho de suas atividades para coibir novos irresponsáveis desastres.

No caso específico dos rompimentos de barragens em análise, verificou-se uma situação de descumprimento das normas de segurança para a preservação do meio ambiente. Tais faltas e descasos tem sido recorrentes, e denuncia uma triste realidade de negligência ou de omissão de responsabilidade por parte das empresas na exploração da atividade, colocando sempre em risco o meio ambientes e sociedade (DIAZ; SANTOS JÚNIOR, 2017, p. 3).

Soma-se ainda, que além do descaso da empresa na manutenção e a falta de fiscalização do Poder Público contribuiu decisivamente para os desastres envolvendo barragens. Faz-se necessário conciliar o crescimento econômico à proteção dos finitos recursos naturais, com vistas ao gerenciamento da problemática de responsabilização pelo dano ambiental, neste âmbito, a punição civil serve também como ferramenta de prevenção e de precaução para futuros riscos e como mecanismo de inibição de comportamentos individuais, antissociais e ilícitos (DIAZ; SANTOS JÚNIOR, 2017, p. 3).

\section{As LiÇÕES APRENDIDAS NO DESASTRE dO ROMPIMENTO DA BARRAGEM DE Miraí-MG}

A atividade minerária é histórica, de utilidade pública, e determinante para o desenvolvimento econômico e social do país, contribuindo com a atração de vários investimentos e de considerável retorno financeiro para a economia (ALVES; SILVA, 2016, p.212). A mineração no Brasil produz e comercializa uma variedade de produtos, aproximadamente 70 minerais, sendo 21 tipos de metais, 4 tipos de combustíveis e 45 tipos de minerais industriais, e da mesma forma, utiliza várias formas e técnicas de extração (LOPES, 2014, p.1).

E a continuidade da atividade mineral é inevitável se a humanidade deseja continuar mantendo um elevado nível de conforto material. Mas, apesar de histórica, essa é possivelmente a atividade econômica com menos cuidados com os problemas ambientais. Pois verifica-se 
que a distância dos centros urbanos e de empreendimentos conscientes favorece tal desleixo, embora algumas mineradoras, como seria de se esperar, tenham progredido bastante no desenvolvimento responsável da atividade, entretanto, de maneira geral, o setor ainda deixa muito a desejar, a exemplo dos vários incidentes nos últimos anos (PENNA, 2009, p.1).

Convém ressaltar que a legislação brasileira está adequada aos princípios internacionais, com destaque para o cumprimento da responsabilidade corporativa, o que agrega não só a responsabilidade por danos ambientais, mas ainda, ao regime de trabalho, à saúde, ao combate à discriminação e à previdência social. Outro ponto é que as grandes empresas mineradoras, por sofrerem constante fiscalização e terem maior capacidade econômica têm buscado a adequação aos requisitos da lei, porém ainda existem vários empreendimentos que exploram o subsolo brasileiro sem nenhuma responsabilidade, devido à falta de um controle governamental, ou mesmo porque acreditam que apesar das leis, as sanções não serão efetivadas (PINHEIRO PEDRO, 2017, p.1).

Diante da essencialidade da atividade, é evidente a necessidade de evoluirmos no contexto da responsabilidade civil, assim como no que se refere aos institutos jurídicos e políticos. Não obstante, é possível perceber os constantes avanços feitos em nossa jurisprudência na esfera da responsabilidade civil e sobre o dever de cuidado violado e quanto à modalidade de risco aplicável. A teoria do risco integral, de fato, é a que melhor se adequa quando se trata de um dano de natureza eminentemente ambiental (CARVALHO, 2016, p.48).

Na tentativa de reparação pelo dano sofrido, principalmente tendo o patrimônio dos atingidos afetados pela lama, foram propostas várias ações de indenização contra a mineradora. De acordo com o STJ, aproximadamente 4 mil demandas, tendo como fundamento a reparação do dano utilizando o arcabouço teórico, a teoria do risco integral, com fulcro Constitucional asseverado no artigo 225 caput e $\S 3^{\circ}$ e ainda, na seara infraconstitucional, o amparo no artigo $14, \S 1^{\circ}$, da Lei n. 6.938/1981.

Noutro giro, em que pese, a teoria mostrar-se altamente eficaz na pronta reparação dos danos, a teoria integral do risco desampara nuan- 
ces específicas, ou seja, as relações entre o agente e a vítima, e ainda, a possibilidade da culpa exclusiva desta na perpetuação do prejuízo, de maneira que não se mostra adequada à maioria dos casos comumente encontrados em nossa experiência cotidiana (CARVALHO, 2016, p.28).

Ainda de acordo com Carvalho (2016, p. 29), a teoria, é viável como alternativa a fim de ser utilizada em "atividades capazes de gerar danos irreparáveis a uma parcela considerável da população, motivo pelo qual foi adotada pelo ordenamento jurídico brasileiro como forma de responsabilização nos danos de cunho ecológico e ambiental".

Interpretando este pensamento, Nelson Nery Júnior (1984, p. 172) leciona que:

A indenização é devida independentemente de culpa e, mais ainda, pela simples razão de existir a atividade da qual adveio o prejuízo: o titular da atividade assume todos os riscos dela oriundos. Dessa maneira, não se operam como causas excludentes de responsabilidade, o caso fortuito e a força maior. Ainda que a indústria tenha tomado todas as precauções para evitar acidentes danosos ao meio ambiente, se, por exemplo, explode um reator controlador de emissão de agentes químicos poluidores (caso fortuito), subsiste o dever de indenizar. Do mesmo modo, se por um fato da natureza ocorrer o derramamento de substância tóxica existente no depósito de uma indústria (força maior), pelo simples fato de existir a atividade há o dever de indenizar.

A mineradora, entre outras justificativas, alegou a inexistência de culpa e de nexo causal, pois de acordo com a linha de defesa traçada, não poderia ser obrigada a indenizar dano que não causou. E o rompimento da barragem havia sido ocasionado por fato fortuito, irreprimível e extraordinário.

Após anos de embate jurídico, resultante da ação proposta, muitos obtiveram na Justiça indenização apenas por danos morais, e, no valor aproximado de $\mathrm{R} \$ 5.000,00$. Conforme as decisões dos processos, tais valores seriam justos e compreensíveis e sobretudo, proporcionais ao 
dano de destruição de seus móveis e casas em virtude da lama. Justificou-se que, em caso de uma indenização de maior valor poderia configurar enriquecimento indevido e, inclusive, inviabilizar a continuidade da empresa, a reparação dos danos das demais pessoas e, ainda, a concretização do plano de reparação ambiental (SUPREMO TRIBUNAL DE JUSTIÇA, 2016, p.1).

Desta forma, em decorrência das várias ações ajuizadas, o STJ julgou o caso em instância de recurso repetitivo aplicando a seguinte tese que consta na ementa do Recurso Especial 1374284 / MG:

RESPONSABILIDADE CIVIL POR DANO AMBIENTAL... ART. 543-C DO CPC. DANOS DECORRENTES DO ROMPIMENTO DE BARRAGEM ... 1. Para fins do art. 543-C do Código de Processo Civil: a) a responsabilidade por dano ambiental é objetiva, informada pela teoria do risco integral, sendo o nexo de causalidade o fator aglutinante que permite que o risco se integre na unidade do ato, sendo descabida a invocação, pela empresa responsável pelo dano ambiental, de excludentes de responsabilidade civil para afastar sua obrigação de indenizar; b) em decorrência do acidente, a empresa deve recompor os danos materiais e morais causados e c) na fixação da indenização por danos morais, recomendável que o arbitramento seja feito caso a caso e com moderação, proporcionalmente ao grau de culpa, ao nível socioeconômico do autor, e, ainda, ao porte da empresa, orientando-se o juiz pelos critérios sugeridos pela doutrina e jurisprudência, com razoabilidade, valendo-se de sua experiência e bom senso, atento à realidade da vida $\mathrm{e}$ às peculiaridades de cada caso, de modo que, de um lado, não haja enriquecimento sem causa de quem recebe a indenização e, de outro, haja efetiva compensação pelos danos morais experimentados por aquele que fora lesado...(SUPREMO TRIBUNAL DE JUSTIÇA, 2014, p.1)

Ademais, a lição aprendida com o desastre do rompimento da barragem de Miraí, também em Minas Gerais, não foi suficiente para evitar 
futuramente outra catástrofe similar. A tragédia de Mariana resultou em um volume ainda maior de rejeitos com um rastro de destruição e um passivo ambiental de proporções ainda muito maiores.

Por sua vez, em termos da responsabilidade civil decorrente do dano ambiental, a jurisprudência do STJ, além de indicar a desnecessidade de se enquadrar a existência ou não de culpa, asseverou que a obrigação de indenizar surge não apenas quando presente a conduta do agente diretamente relacionada ao dano, no clássico binômio de causa e efeito, mas também quando o dano é provocado pelos fatores de risco da atividade.

Neste contexto, como é cediço a aplicação do instituto da responsabilidade civil nestas situações de rompimento de barragens com dano ambiental, pouco importa a existência ou não de culpa da mineradora ou mesmo a causa do rompimento da barragem, seja qual for o caso. Havendo o dano decorrente dos fatores de risco da atividade de mineração, segundo o entendimento do STJ, surgirá a obrigação de indenizar.

Outra importante vertente que não pode ser dissociada nestes graves acidentes ambientais, está a análise da culpabilidade das mineradoras, dos seus administradores, bem como do próprio Poder Público, quer por ato omissivo ou comissivo, serve a apurar a responsabilização pessoal, civil, administrativa ou criminal.

Em síntese, espera-se que com a aplicação devida das sanções de natureza de responsabilidade civil por danos ambientais, desincentive omissões e negligências com as atividades, em especial, no que se refere a responsabilidade na construção e manutenção de barragens de resíduos de mineração.

\section{Considerações finais}

O trabalho ocupou-se de fazer uma breve reflexão sobre a responsabilidade civil por danos ambientais à luz dos litígios, em especial o REsp 1374284 / MG, motivado pelo desastre com o rompimento da barragem da empresa Mineração Rio Pomba e Cataguases Ltda.

Não se espera limitar as atividades de empresas de mineração, atividade esta essencial e histórica em nosso país. Porém, há sim, a 
evidente a necessidade de evoluirmos no contexto de aprimorarmos a aplicação da responsabilidade civil, a ser pensado de maneira sustentável, como forma de evitar desastres ambientais com barragens, e que possa ser exemplo a coibir novas irresponsabilidades no setor.

Aplicado o instituto da responsabilidade civil, restando comprovada que a atividade foi responsável pelo risco e comprovado o nexo de causalidade entre a atividade e os danos ambientais. Nas situações de rompimento de barragens com dano ambiental, apoiada nos fatores de risco da atividade de mineração, e consoante a teoria da responsabilidade objetiva, eis que surge a obrigação de indenizar.

E assim, a partir do recurso repetitivo do REsp 1374284 / MG pode se homogeneizar os valores obtidos, sendo em geral obtido danos apenas de ordem moral no valor aproximado de $\mathrm{R} \$ 5.000,00$, o qual foi justificado por não inviabilizar a continuidade da empresa, entre outros fatores.

A responsabilidade é essencial para os empreendimentos e deve se pautar sempre no binômio, desenvolvimento e proteção ao meio ambiente. E a aplicação da responsabilização civil no caso de Miraí, não foi capaz de gerar um aprendizado e intimidar que o reiterado descaso com o tratamento dos rejeitos fossem devidamente observados.

Em comum os acidentes guardam relações de semelhança, como exemplo, a falta de manutenção e supervisão técnica dos empreendimentos, o despreparo para lidar em situações de emergência, bem como a própria indefinição de responsabilidades, entre outros aspectos.

É evidente que não se poderá voltar ao estado antes dos desastres, e que as indenizações paguem integralmente toda e qualquer forma de dano sofrido, mas é justo que a responsabilização sirva de modelo para outras empresas não se omitam do zelo com a atividade para evitar novos desastres.

Não restam dúvidas de que as aplicações exemplares das sanções cabíveis pela responsabilidade civil pelo dano ocasionado devem continuar sendo gradativamente aprimoradas, como meio também para observância dos devidos cuidados e responsabilidade com a construção e manutenção de barragens. 


\section{REFERENCIAS}

ALVES, Leila Cristina do Nascimento. SILVA, Romeu Faria Thomé da. As respostas jurídicas do Estado de Minas Gerais aos acidentes com barragens de rejeitos da mineração. In: $\mathbf{2 5}^{\circ}$ Congresso do CONPEDI - Curitiba. Direito e sustentabilidade IV [Recurso eletrônico on-line] organização CONPEDI/UNICURITIBA. Coordenadores: Belinda Pereira da Cunha, Fernando Joaquim Ferreira Maia. Curitiba: CONPEDI, 2016. Disponível em: < https://www. conpedi.org.br/publicacoes/02q8agmu/j397m28a/6o2H6S8Era112pOd.pdf $>$. Acesso em: 01 ago. 2017.

AMADO, Frederico A. Di Trindade. Direito ambiental esquematizado. 5. ${ }^{\text {a }}$ ed. - Rio de Janeiro: Forense; São Paulo: MÉTODO, 2014.

BELCHIOR, Germana Parente Neiva; BRAGA, Lara Facó Santos; THEMUDO, Tiago Seixas. A responsabilidade civil por danos ambientais: um ano após o desastre ocorrido em Mariana/MG. Universitas Jus, v. 27, n. 3, 2016.

BENJAMIN, Antonio Herman de Vasconcellos. O princípio poluidor-pagador e a reparação do dano ambiental. BDJur. Brasília, 1993. Disponível em: $<$ https://bdjur.stj.jus.br/jspui/handle/2011/8692? mode=full $>$. Acesso em: 01 ago. 2017.

BOUTH, Sandro. O princípio da responsabilidade no direito ambiental. Natura non facit saltum. 2011. Rio de Janeiro. Disponível em: $<$ http://analiseambiental.blogspot.com.br/2011/06/o-principio-da-responsabilidade-no.html >. Acesso em: 01 ago. 2017.

CARVALHO, Mateus H. Andrade. O caso Mariana-MG e a Responsabilidade Civil da União frente aos demais entes federados. Universidade de Brasília. UnB. Brasília, 2016. Disponível em: < http://bdm.unb.br/bitstream/10483/15019/1/2016 MateusHenriqueAndradedeCarvalho.pdf $>$. Acesso em: 01 ago. 2017.

DIAZ, Louise Almeida Y; SANTOS JUNIOR, Selmo Alves dos Santos Júnior et al. A responsabilidade civil do Estado frente aos danos ocorridos pelo rompimento da barragem da mineradora Samarco em Mariana/MG. Revista Jus Navigandi, ISSN 1518-4862, Teresina, ano 22, n. 5093, 11 jun. 2017. Disponível em: <https://jus.com.br/artigos/58366>. Acesso em: 2 ago. 2017. 
FERREIRA, Diógenes Gamaliel; DO ESPÍRITO SANTO, Raquel. Responsabilidade Civil ao dano ambiental no caso da mineradora Rio Pombo. JICEX, v. 8, n. 8, Curitiba, 2017. Disponível em: < http://www.egov.ufsc.br/portal/ sites/default/files/1775-1583-1-pb.pdf > . Acesso em: 01 ago. 2017.

FREITAS, Vladimir Passos de. Segunda Leitura. Desastre em Mariana mudará práticas de empreendimentos de risco. Consultor Jurídico. Conjur. São Paulo, 2016. Disponível em: < http://www.conjur.com.br/2015-nov-22/segunda-leitura-desastre-mariana-mudara-praticas-empreendimentos-risco $>$. Acesso em: 01 ago. 2017.

LARCHER, Marta Alves. A Responsabilidade Civil decorrente de acidentes ambientais deflagrados por eventos da natureza - $\mathrm{O}$ caso do rompimento da barragem de rejeitos em Miraí. Ministério Público de Minas Gerais. Coordenadoria Estadual das Promotorias de Justiça de Defesa da Habitação e Urbanismo. Belo Horizonte. 2012. Disponível em: < https://aplicacao.mpmg. mp.br/xmlui/bitstream/handle/123456789/1088/8\%20R\%20MJ\%20Responsabilidade $\% 20$ civil $\% 20-\% 20$ marta.pdf? sequence $=1$ >. Acesso em: 01 ago. 2017.

LOPES, Marcos. Mineração no Brasil atual e sua influência na Economia Nacional. Técnico e Mineração. Belo Horizonte, 2014. Disponível em: < http:// tecnicoemineracao.com.br/mineracao-brasil-atual-e-sua-influencia-na-economia-nacional/ >. Acesso em: 01 ago. 2017.

MACHADO, Igor Suzano. Comunidade de princípios e princípio responsabilidade: o juiz Hércules confuso diante de uma natureza ameaçada. Revista Veredas do Direito, Belo Horizonte, v. 13, n. 27, p. 243-265, set./ dez. 2016. Disponível em: < http://www.domhelder.edu.br/revista/index.php/veredas/article/view/860/524 >. Acesso em: 02 ago. 2017.

MILARÉ, Edis. Direito do Ambiente: doutrina, jurisprudência e glossário. $5^{\text {a }}$ edição rev. atual. e ampl. - São Paulo: Editora Revista dos Tribunais, 2007.

NERY JR, Nelson. Responsabilidade civil por dano ecológico e a ação civil pública. São Paulo: Justitia, 1984.

PENNA, Carlos Gabaglia. Efeitos da mineração no meio ambiente. Associação o ECO. Rio de Janeiro, 2009. Disponível em: < http://www.oeco.org.br/ colunas/carlos-gabaglia-penna/20837-efeitos-da-mineracao-no-meio-ambien- 
te/ >. Acesso em: 01 ago. 2017.

PINHEIRO PEDRO, Fernando. Mineradoras devem gerar benefícios sustentáveis. Panorama da importância da mineração no Brasil face à necessidade de se garantir a sustentabilidade. Pinheiro Pedro Advogados. São Paulo. 2017. Disponível em: < http://www.dazibao.com.br/site/mineradoras-devem-gerar-beneficios-sustentaveis/ $>$. Acesso em: 01 ago. 2017.

PISKE, Oriana. Mariana: De quem é a responsabilidade pelo maior desastre ambiental brasileiro? Tribunal de Justiça do Distrito Federal e Territórios. TJDFT. Brasília, 2016. Disponível em: < http://www.tjdft.jus.br/institucional/ imprensa/artigos/2016-1/mariana-de-quem-e-a-responsabilidade-pelo-maior-desastre-ambiental-brasileiro-juiza-oriana-piske >. Acesso em: 01 ago. 2017.

SANTIAGO, Luciana Silva. SANTOS, Douglas W. da Silva dos. ADAME, Alcione. Mariana e a responsabilidade ambiental. Faculdade de Ciências Contábeis e Administração do Vale do Juruena - AJES. Juína, 2016. Disponível em: < http://site.ajes.edu.br/encontro/arquivos/20160821083051.pdf $>$. Acesso em: 01 ago. 2017.

SILVA, Mauro Cipriano da. Desastre Ambiental Indenização. Azevedo Sette Advogados. São Paulo, 2007. Disponível em: < http://www.azevedosette. com.br/pt/noticias/desastre_ambiental_indenizacao/856 >. Acesso em: 01 ago. 2017.

SILVA, Romeu Faria Thomé da. Manual de Direito Ambiental. 5 Edição, Salvador: Editora JusPodivm, 2015.

STEIGLEDER, Annelise Monteiro. Responsabilidade Civil Ambiental: as dimensões do dano ambiental no direito brasileiro. 2 ed. Porto Alegre: Livraria do Advogado, 2011.

SOUSA, Deisy de. O Princípio do Poluidor-Pagador e sua Aplicabilidade. JusBrasil. Salvador. 2016. Disponível: < https:/emdeis.jusbrasil.com.br/ artigos/311776167/o-principio-do-poluidor-pagador-e-sua-aplicabilidade $>$. Acesso em: 01 ago. 2017.

SUPREMO TRIBUNAL DE JUSTIÇA. Recurso Especial n 1.374.284 - MG (2012/0108265-7). Supremo Tribunal de Justiça. STJ. Relator Ministro Luis Felipe Salomão. Data de Julgamento: 27/08/2014, Data de Publicação: DJe 05/09/2014. Brasília. 2014. Disponível em: < https:/ww2.stj.jus.br/processo/ 
pesquisa/?src=1.1.3\&aplicacao $=$ processos. ea\&tipoPesquisa $=$ tipoPesquisaGen erica\&num_registro=201201082657 >. Acesso em: 01 ago. 2017.

SUPREMO TRIBUNAL DE JUSTIÇA. Recurso Especial no 1373788 - SP (2013/0070847-2). Supremo Tribunal de Justiça. STJ. Relator: Ministro Paulo de Tarso Sanseverino. Data de Julgamento: 06/05/2014, T3 - Terceira Turma, Data de Publicação: DJe 20/05/2014. Brasília.2014. Disponível em: < http://www.stj.jus.br/SCON/jurisprudencia/doc.jsp?livre=1373788+\&b=ACO $\mathrm{R} \& \mathrm{p}=$ true \&l=10\&i=5 >. Acesso em: 01 ago. 2017.

SUPREMO TRIBUNAL DE JUSTIÇA. Segunda Seção decide que mineradora é responsável por dano ambiental ocorrido em MG. Supremo Tribunal de Justiça. STJ. Brasília. 2014. Disponível em: < https://stj.jusbrasil.com. br/noticias/136827715/segunda-secao-decide-que-mineradora-e-responsavel-por-dano-ambiental-ocorrido-em-mg>. Acesso em: 01 ago. 2017.

\section{SOBRE OS AUTORES}

\section{Marcos Vinicius Rodrigues}

Mestrando em Direito Ambiental e Desenvolvimento Sustentável. Escola Superior Dom Helder Câmara, ESDHCl. Especialização em LLM Direito Empresarial. Faculdade IBS - Business School de Minas Gerais, IBS. Especialização em Direito Processual Civil. Universidade para o Desenvolvimento do Estado e da Região do Pantanal, UNIDERP. Graduação em Direito. Universidade Federal de Minas Gerais, UFMG. Graduação em Ciência da Computação. Universidade Federal de Uberlândia, UFU. Membro do Grupo de Pesquisa Responsabilidade Civil por Danos ao Meio Ambiente.

|E-mail: marcos@lawyer.com.

Submetido em:16-5-2018

Aceito em:29-11-2018 